\title{
Analysis of stage-specific protein synthesis during spermatogenesis of the mouse by two-dimensional gel electrophoresis
}

\author{
J. M. Kramer and R. P. Erickson \\ Department of Human Genetics, University of Michigan Medical School, Ann Arbor, Michigan \\ 48109, U.S.A.
}

\begin{abstract}
Summary. Cells were labelled by intratesticular injection of $\left[{ }^{35} \mathrm{~S}\right]$ methionine. After 14-16 $\mathrm{h}$ the relative rates of incorporation of label in spermatocytes, early spermatids and late spermatids were $10: 2: 1$ respectively. Approximately $15 \%$ of the soluble ( $100000 \mathrm{~g}$ supernatant) and $20 \%$ of the particulate proteins solubilized by NP-40 (from the $100000 \mathrm{~g}$ pellet) that were detectable on two-dimensional gels showed stage-specific synthesis. A large number of proteins were detectable only in post-meiotic cells and may be valuable for studying the control of gene expression in haploid cells.
\end{abstract}

\section{Introduction}

The process of spermatogenesis entails extensive morphological and biochemical alterations resulting in the production of fully differentiated spermatozoa. Many proteins which are unique to spermatogenic cells have been described (see 'Discussion'). Some of these proteins appear before meiosis while others appear sometime after meiosis. It is of interest to know whether there are many sperm specific proteins and when during the course of spermatogenesis they appear. These proteins may be valuable as markers of specific spermatogenic stages and may provide a means to study the regulatory mechanisms which are operative in spermatogenesis.

We have therefore analysed the proteins synthesized in spermatocytes, early spermatids and late spermatids.

\section{Animals}

\section{Materials and Methods}

The mice were CD-1 males of $>10$ weeks of age and purchased from Charles River or random-bred from their stock. The animals were maintained under $14 \mathrm{~h}$ light $/ 24 \mathrm{~h}$ with pelleted diet and water always available.

\section{Materials}

Acrylamide and agarose were obtained from Bio-Rad Laboratories. L- $\left[{ }^{35} \mathrm{~S}\right]$ Methionine (sp. act. 900-1200 Ci/mmol; Radiochemical Centre, Amersham, U.K.) was used for all protein labelling studies. Specially pure sodium lauryl sulphate was obtained from BDH (Poole, U.K.) and ultra-pure urea was from Schwartz-Mann (Orangeburg, New York). Trypsin and 
Dulbecco's phosphate-buffered saline (PBS) were from GIBCO (New York, U.S.A.). Ampholines were from LKB (Bromma, Sweden). All other reagents were obtained from Sigma Chemical Co. (St Louis, Missouri, U.S.A.).

\section{Testicular labelling}

Mice were anaesthetized with pentobarbitone sodium and a small incision was made through the lower abdominal wall to allow access to the testes. Each testis was injected with 15-20 $\mu \mathrm{l}$ $100 \mu \mathrm{Ci}\left[{ }^{33} \mathrm{~S}\right]$ methionine (neutralized with $1 \mathrm{~N}-\mathrm{NaOH}$ and buffered with PBS). The incision was closed with wound clips. After a 14-16 h labelling period the animals were killed and testes removed.

\section{Cell preparation and centrifugal elutriation}

Testes were decapsulated and the intact tubules incubated at $32^{\circ} \mathrm{C}$ for $10 \mathrm{~min}$ in phosphate-buffered saline, $\mathrm{pH} 7.2$, containing $0.1 \%$ trypsin and $0.025 \%$ EDTA. The solution was streamed between the tubules with a Pasteur pipette to remove interstitial cells and separate the tubules. The tubules were washed twice with phosphate-buffered saline before preparation of a cell suspension as described by Grabske, Lake, Gledhill \& Meistrich (1975). Centrifugal elutriation was performed as described by Grabske et al. (1975). Cellular viability was assayed by trypan blue exclusion. The purity of cell fractions was assessed from smears fixed in methanol : acetic acid $(3: 1 \mathrm{v} / \mathrm{v})$ and stained with toluidine blue or Giemsa.

\section{Sonication and determination of $\left[{ }^{35}\right.$ S $]$ methionine incorporation}

Cell pellets were sonicated on ice in a buffer of $10 \mathrm{~mm}$-Tris (pH 7.2), $5 \mathrm{~mm}-\mathrm{MgCl}_{2}, 1$ mM-dithiothreitol and $1 \mathrm{~mm}$-phenyl methyl sulphonyl fluoride with a Branson Sonifer $(30 \mathrm{sec}$, $30 \%$ pulsed cycle, power setting 3). The sonicates were centrifuged at $100000 \mathrm{~g}$ for $60 \mathrm{~min}$; the supernatant was carefully removed and used as the soluble fraction. The pellet was washed once with sonication buffer, then re-sonicated in the same buffer containing $0.5 \% \mathrm{NP}-40$, centrifuged at $40000 \mathrm{~g}$ for $30 \mathrm{~min}$ and the supernatant saved as the particulate fraction solubilized by NP-40.

Total $\left[{ }^{35} S\right]$ methionine incorporation was determined by precipitating small aliquots of the soluble supernatants in 10\% trichloroacetic acid (TCA), collecting on Whatman GF/C filters and washing with $5 \% \mathrm{TCA}$ and ice-cold $100 \%$ ethanol. The filters were dried and counted in Insta-Gel (Packard Instrument Company).

\section{Two-dimensional polyacrylamide gel electrophoresis}

DNA and RNA present in the soluble supernatants were digested by adding $0.25 \mathrm{mg}$ DNAse $/ \mathrm{ml}$ and $0.25 \mathrm{mg}$ RNAse $/ \mathrm{ml}$ to the samples. Further sample and gel preparation were as described by O'Farrell (1975) except that isoelectric focussing was done with $9 \mathrm{M}$-urea, in $130 \times$ $3.5 \mathrm{~mm}$ tubes and second-dimension sodium dodecyl (lauryl) sulphate gels contained $10 \%$ acrylamide. Each gel was loaded with 150000 c.p.m. as determined by trichloroacetic acid precipitation.

Gels were fixed and washed with a large volume of $50 \%$ ethanol, $7.5 \%$ acetic acid and $1 \%$ trichloroacetic acid; stained in a solution of $10 \%$ ethanol, $7.5 \%$ acetic acid, $1 \%$ trichloroacetic acid and $0.005 \%$ Coomassie Blue R; and then de-stained with several changes of a solution of $10 \%$ ethanol and $7.5 \%$ acetic acid. Dried gels were exposed to Kodak X-Omat XR-5 film at $-70^{\circ} \mathrm{C}$ for 21 days. 


\section{Results}

\section{Purity of cell fractions}

The spermatocyte fractions consisted of $60-70 \%$ pachytene spermatocytes with the major contaminant being multinucleated early spermatids. Early spermatid fractions (Stages I-VIII) contained $70-80 \%$ early spermatids with the major contaminants being late spermatids and cytoplasmic fragments. Late spermatid fractions (Stages IX-XVI) were contaminated with $30-35 \%$ cytoplasmic fragments and residual bodies. Viability of cells after fractionation was always greater than $85 \%$ as determined by trypan blue exclusion.

\section{Relative incorporation of $\left[{ }^{35} S\right]$ methionine}

In four separate experiments incorporation of $\left[{ }^{35} \mathrm{~S}\right]$ methionine into trichloroacetic acidprecipitable material was determined on separated testicular cell fractions (Table 1). Total incorporation on a per cell basis varied between experiments, possibly because of differences in the retention of $\left[{ }^{35} \mathrm{~S}\right]$ methionine within the testis capsule. However, the relative incorporation by the different cell fractions was very consistent. To facilitate comparison between cell fractions, incorporation relative to the late spermatid fraction was calculated for each experiment and is presented in Table 1. Expressed on a per cell basis, pachytene spermatocytes incorporated approximately 5 times more $\left[{ }^{35} \mathrm{~S}\right]$ methionine than did early spermatids and 10 times more than did late spermatids.

Table 1. Incorporation of $\left[{ }^{35} \mathrm{~S}\right]$ methionine into mouse spermatogenic cells

\begin{tabular}{|c|c|c|c|c|c|c|}
\hline \multirow{2}{*}{ Cell type } & \multicolumn{5}{|c|}{ TCA-precipitable incorporation (c.p.m. $\times 10^{-4}$ per $10^{6}$ cells) } & \multirow{2}{*}{$\begin{array}{l}\text { Incorpora- } \\
\text { tion* relative } \\
\text { to late } \\
\text { spermatids }\end{array}$} \\
\hline & Exp. I & Exp. II & Exp. III & Exp. IV & Mean \pm s.e.m. & \\
\hline Late spermatids & 3.4 & 1.9 & 1.5 & $1 \cdot 2$ & $2.0 \pm 0.49$ & 1.0 \\
\hline Early spermatids & $6 \cdot 3$ & $5 \cdot 8$ & 1.8 & $2 \cdot 5$ & $4 \cdot 1 \pm 2 \cdot 3$ & $2 \cdot 1 \pm 0.39$ \\
\hline Pachytene spermatocytes & $36 \cdot 2$ & $28 \cdot 2$ & $9 \cdot 0$ & $8 \cdot 5$ & $20.5 \pm 6.9$ & $9 \cdot 6 \pm 2 \cdot 0$ \\
\hline
\end{tabular}

* Calculated by dividing all values in an experiment by the late spermatid value for that experiment. The mean \pm s.e.m. for these relative values is presented.

\section{Comparison of two-dimensional gel patterns}

Proteins with isoelectric points between $\mathrm{pH} 4.5$ and 8.0 and with molecular weights between 20000 and 150000 can be reliably analysed with the gel system used. Approximately 200-300 spots were readily distinguishable on the autoradiograms and their shape and position are highly reproducible. For comparison of cell fractions, only clearly resolved spots were considered and only absolute differences or large quantitative differences $(\geq 80 \%)$ in spot intensity were analysed. Many lesser quantitative differences were apparent but not considered: strong spots appeared strong on all gels, spots of intermediate intensity varied between gels but were always present, and weak spots were sometimes undetectable on particular gels. Therefore, it was necessary to compare gels from several experiments to identify stage-specific spots confidently.

Autoradiograms of supernatant proteins from pachytene spermatocyte, early spermatid and late spermatid fractions are shown in Pl. 1, Figs 1-3, respectively. The largest class of proteins was present to some extent in all three cell populations and represented approximately $85 \%$ of the total number of spots. A group of 20 proteins was clearly present only in the early and late spermatid fractions. These proteins also varied quantitatively; some were maximal in early spermatids, some in late spermatids and some were equally represented in early and late spermatids. Four proteins were detected only in the pachytene spermatocytes and three were 
present in spermatocytes and early spermatids but not in late spermatids. Ten proteins were found only in early spermatids while only one protein appeared specific to late spermatids.

Autoradiograms of the particulate proteins soluble in NP-40 from pachytene spermatocytes and from early and late spermatids are illustrated in Pl. 2, Figs 4-6, respectively. Again, most proteins $(75-80 \%)$, were found in all three cell populations. Eight proteins were present in early and late spermatids but not in pachytene spermatocytes. All of these proteins appeared to be in greater abundance in late than in early spermatids. Three of these proteins ran to the same positions as did the three most prominent supernatant proteins that were specific to early and late spermatids, and may have been due to contamination of the particulate preparations with supernatant proteins. Ten proteins were specific to pachytene spermatocytes and seven were found in spermatocytes and early spermatids but not in late spermatids. Seven proteins were specific to early spermatids and six to late spermatids.

\section{Discussion}

The in-vivo labelling studies presented here indicate that on a per cell basis incorporation of $\left[{ }^{35} \mathrm{~S}\right]$ methionine decreased approximately 5 -fold from the pachytene spermatocyte stage to the early spermatid stage and drops another 2-fold in the late spermatid stage. These results are consistent with an autoradiographic study which demonstrated decreasing ${ }^{3} \mathrm{H}$-labelled amino acid incorporation throughout spermatogenesis (Monesi, 1965). DNA content (by meiosis) and poly(A)-RNA synthesis decrease 4-fold between pachytene spermatocytes and early spermatids (Geremia, D’Agostino \& Monesi, 1978; Erickson, Erickson, Betlach \& Meistrich, 1980). Therefore, the relative incorporation of $\left[{ }^{35} \mathrm{~S}\right]$ methionine into protein is essentially identical for pachytene spermatocytes and early spermatids, based on either of these criteria. A decline in the synthesis of poly(A)-RNA has been demonstrated in late spermatids, but stable RNAs apparently can be preserved throughout spermiogenesis to the late spermatid stage (Geremia, Boitani, Conti \& Monesi, 1977). A portion of the protein synthesis observed in late spermatids in this study may result from translation of such stable mRNAs. However, there are increases in the levels of translatable mRNA for two sperm-specific proteins, phosphoglycerate kinase- 2 and protamine-like histone, in late spermatids (Erickson, Kramer, Rittenhouse \& Salkeld, 1980). This suggests that protein synthesis in late spermatids may also result from concurrently synthesized mRNAs. In any event, this study demonstrates that $\left[{ }^{35} \mathrm{~S}\right]$ methionine incorporation does continue in late spermatids at about one-half the rate in early spermatids.

Analysis of the protein synthesized by these three cell populations on two-dimensional gels revealed several distinct patterns of protein appearance. Most proteins (75-80\%) were found in

\section{PLATE 1}

Figs 1-3. Autoradiograms of two-dimensional gels of soluble ( $100000 \mathrm{~g}$ supernatant) proteins synthesized by pachytene spermatocytes (Fig. 1), early spermatids (Fig. 2) and late spermatids (Fig. 3). The location of phosphoglycerate kinase-2 is indicated by $a$. Specific proteins are indicated as those present in pachytene spermatocytes only ( $\square$ ); those present in pachytene spermatocytes and early spermatids only $(\{\})$; those present in early and late spermatids but not in pachyene stages $(\mathbf{O})$; and those present only in early or late spermatids (A).

\section{PLATE 2}

Figs 4-6. Autoradiograms of two-dimensional gels of particulate proteins (100000 $\mathrm{g}$ pellet solubilized by NP-40) synthesized by pachytene spermatocytes (Fig. 4), early spermatids (Fig. 5) and late spermatids (Fig. 6). Specific proteins are indicated as those present in pachytene spermatocytes only ( $\square$; ; those present in pachytene spermatocytes and early spermatids only ( \{\} ; those present in early and late spermatids but not in pachytene stages $(O)$; and those present only in early or late spermatids $(\boldsymbol{\Delta})$. 
PLATE 1

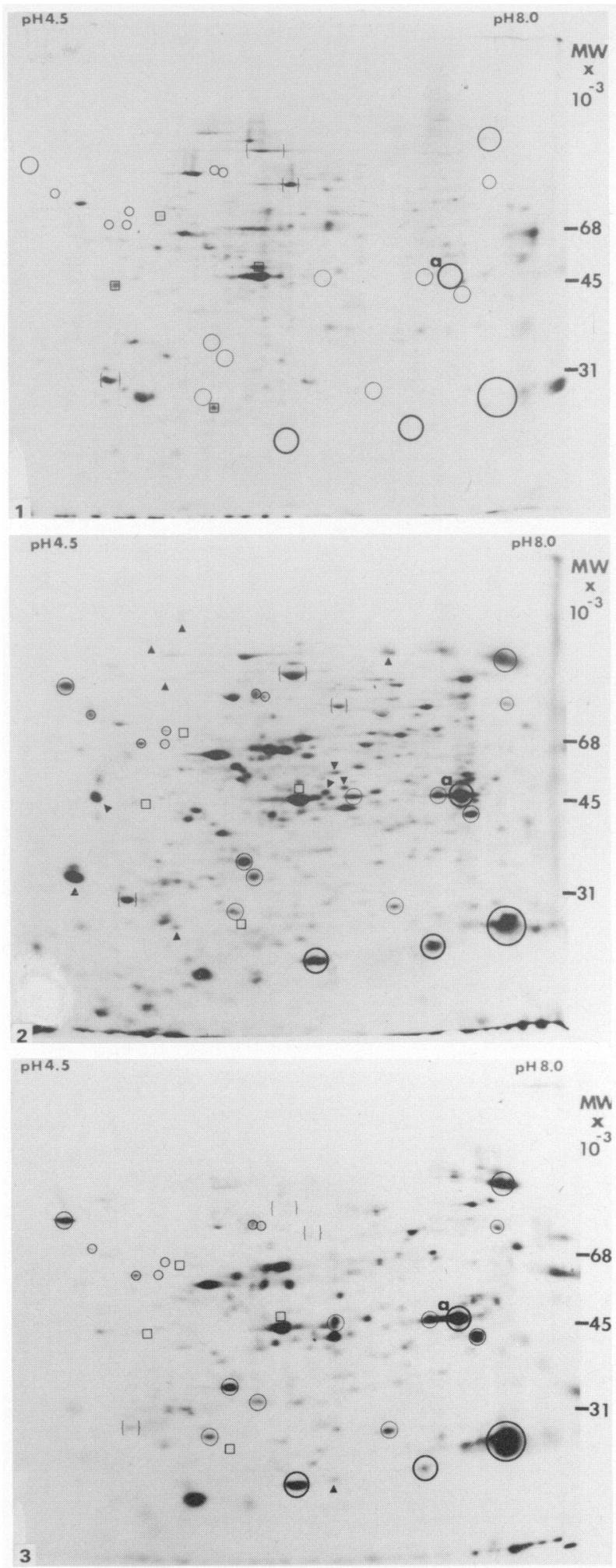

(Facing p. 142) 
PLATE 2

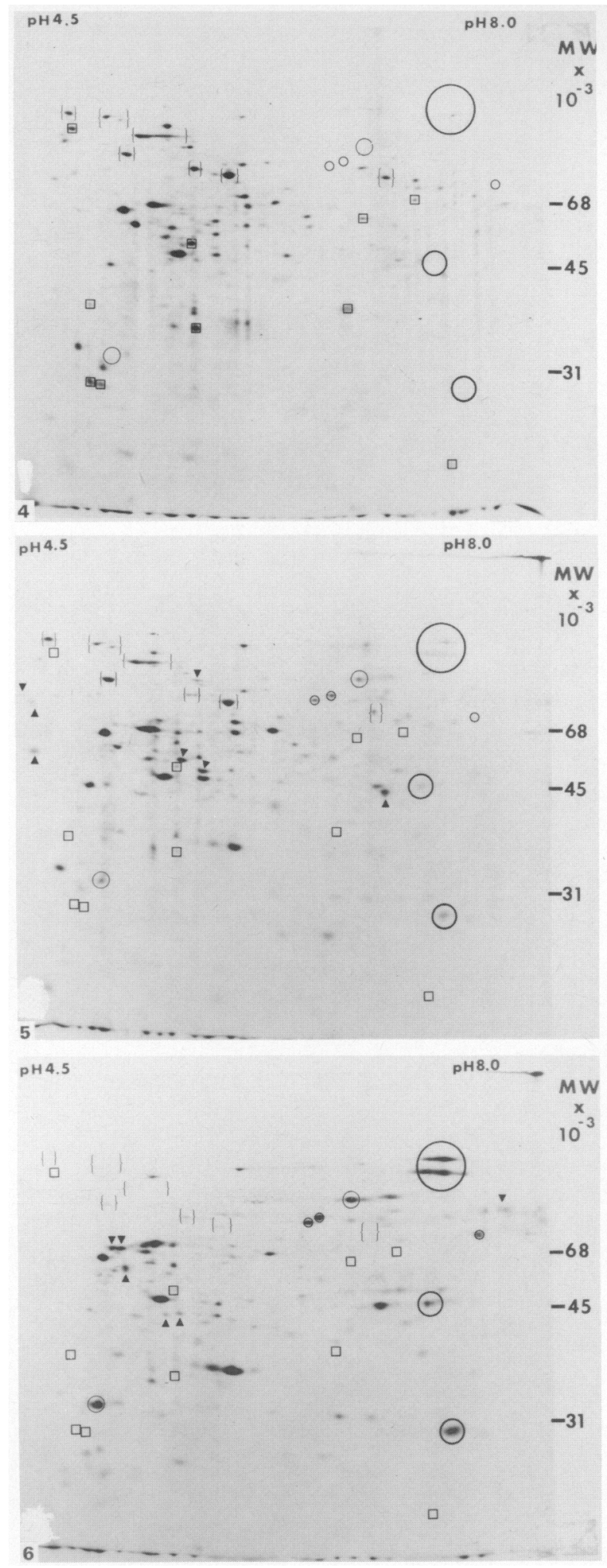


all three cell populations for both soluble and particulate fractions although many of these proteins showed some quantitative variation. Approximately $10-15 \%$ of these proteins were found only in post meiotic cells while only $5-10 \%$ were found exclusively in the pachytene spermatocytes or in pachytene and early spermatids. These numbers represent minimal estimates for the number of stage-specific proteins because the cell fractions were not pure. Cross-contamination between fractions would have obscured rather than created differences. This amount of qualitative variation between testicular cell types is similar to that found in other analyses with two-dimensional gels; a comparison of mouse liver and kidney proteins revealed approximately $10 \%$ qualitative variation (Elliott, 1979) and $5 \%$ variation was detected between a nerve and a glial cell line (Garrels, 1979).

Comparison of the soluble supernatant and that of particulate proteins solubilized by NP40 indicates a different trend of appearance for those proteins found only in post-meiotic cells. In the soluble fraction, there were 10 proteins specific to early spermatids but only 1 specific to late spermatids; the quantitative variation of proteins found in the spermatids was not skewed towards the early or late stages. In the particulate fraction, 7 proteins were specific to early, 6 to late spermatids and proteins found in both of these but not in pachytene cells were all quantitatively greater in late spermatids. This suggests that late in spermiogenesis a relatively large number of new structural and membrane-associated proteins are synthetized, possibly reflecting the profound morphological rearrangements which occur during this period. This is supported by a study of the time of synthesis of proteins present in sperm which demonstrates a relatively high synthesis rate for sperm structural proteins during mid-late spermiogenesis (O'Brien \& Bellvé, 1980a, b). Our 'rough' separation of proteins into soluble (100000 g supernatant) and particulate (solubilized by NP-40 from the $100000 \mathrm{~g}$ pellet) types produces quite distinctive two-dimensional gel electrophoresis patterns. Again, these must be minimal differences because significant absorption of soluble proteins into sedimentable particles would decrease the apparent differences.

Several sperm-specific enzymes have been identified which may be synthesized postmeiotically; these include hexokinase (Sosa, Altamirano, Hernández \& Rosado, 1972), hyaluronidase (Mancini, Alonso, Barquet, Alvarez \& Nemirovsky, 1964; Males \& Turkington, 1970), cyclic nucleotide phosphodiesterase (Christiansen, Monn \& Desautel, 1972), acrosin (Stambough \& Buckley, 1969), phosphoglycerate kinase-2 (PGK-2) (VandeBerg, Cooper \& Close, 1977), and lactate dehydrogenase-X (LDH-X) (Blanco \& Zinkham, 1963). Actual quantitation of synthesis has been accomplished only for LDH-X (Meistrich, Trostle, Frapart \& Erickson, 1977) for which the rate of synthesis is highest in pachytene spermatocytes and declines throughout spermiogenesis. We have identified PGK-2 in our two-dimensional gel system (designated $a$ in Plate 1) by the co-migration of both specific immunoprecipitates and purified enzyme (Kramer \& Erickson, 1981). It can be seen that PGK-2 synthesis is not detected in pachytene spermatocytes but is highly abundant in both early and late spermatids. This is consistent with the fact that PGK-2 activity is first detectable when early spermatids appear and increases in activity in later spermatids (VandeBerg et al., 1977; Kramer \& Erickson, 1981).

Boitani, Geremia, Rossi \& Monesi (1980) have reported a similar study of spermatogenic cells using two-dimensional gel electrophoresis but with somewhat different results. Boitani et al. (1980) found approximately 150 spots which were present in spermatocytes and round spermatids (I-VIII) but not present in intermediate spermatids (IX-XIII) while we detected only 10 such spots. This may be the result of differences in experimental technique. Our labelling was performed in vivo for 14-16 h while Boitani et al. (1980) labelled in vitro for $3 \mathrm{~h}$; we ran all gels identically (150000 c.p.m. and 21-day exposure) while Boitani et al. (1980) varied exposure times. Finally, Boitani et al. (1980) ran $100000 \mathrm{~g}$ supernatant and particulate proteins solubilized by NP-40 together; we obtained improved resolution if they were run separately.

Our study identifies a large number of proteins for which the rates of $\left[{ }^{35} \mathrm{~S}\right]$ methionine incorporation were significantly altered during the course of spermiogenesis. In particular, we 
identified 52 proteins on two dimensional gels which were detectable only in haploid spermatid cells. We are now investigating whether the synthesis of these proteins is controlled at the transcriptional or post-transcriptional level.

This work was supported by Genetics Training Grant GM 7544 and Research Grant HD 11738 to R.P.E. We thank Mrs Rena Jones for excellent secretarial assistance. This work was submitted by J.M.K. in partial fulfilment of the requirements for the Ph.D. degree at The University of Michigan.

\section{References}

Blanco, A. \& Zinkham, W.H. (1963) Lactate dehydrogenases in human testes. Science, N.Y. 139, 601602.

Boitani, C., Geremia, R., Rossi, R. \& Monesi, V. (1980) Electrophoretic pattern of polypeptide synthesis in spermatocytes and spermatids of the mouse. Cell Differen. 9, 41-49.

Christiansen, R.O., Monn, E. \& Desautel, M. (1972) Highly specific testicular isozyme of cyclic nucleotide phosphodiesterase associated with sexual maturation. Clin. Res. 20, 252.

Elliott, R.W. (1979) Comparison of soluble proteins from mouse kidney and liver using two-dimensional electrophoresis. Fedn Proc. Fedn Am. Soc. exp. Biol. 38, 330, Abstr.

Erickson, R.P., Erickson, J., Betlach, C.J. \& Meistrich, M.L. (1980) Further evidence for haploid gene expression during spermatogenesis: heterogeneous, poly(A)-containing RNA is synthesized postmeiotically. J. exp. Zool. 214, 13-19.

Erickson, R.P., Kramer, J.M., Rittenhouse, J. \& Salkeld, A. (1980) Quantitation of messenger RNA's during mouse spermatogenesis: protamine-like histone and phosphoglycerate kinase-2 mRNAs increase after meiosis. Proc. natn. Acad. Sci. U.S.A. 77, 60866090.

Garrels, J.I. (1979) Two-dimensional gel electrophoresis and computer analysis of proteins synthesized by clonal cell lines. J. biol. Chem. 254, 7961-7977.

Geremia, R., Boitani, C., Conti, M. \& Monesi, V. (1977) RNA synthesis in spermatocytes and spermatids and preservation of meiotic RNA during spermiogenesis in the mouse. Cell Differen. 5, 343-355.

Geremia, R., D'Agostino, A. \& Monesi, V. (1978) Biochemical evidence of haploid gene activity in spermatogenesis of the mouse. Expl Cell Res. 111 , 23-30.

Grabske, R.J., Lake, S., Gledhill, B.L. \& Meistrich, M.L. (1975) Centrifugal elutriation: separation of spermatogenic cells on the basis of sedimentation velocity. J. Cell Physiol. 86, 177-190.
Kramer, J.M. \& Erickson, R.P. (1981) Developmental program of PGK-1 and PGK-2 isozymes in spermatogenic cells of the mouse: specific activities and rates of synthesis. Devl Biol. (in press).

Males, J.L. \& Turkington, R.W. (1970) Hormonal regulation of hyaluronidase during spermatogenesis in the rat. J. biol. Chem. 245, 6329-6334.

Mancini, R.E., Alonso, A., Barquet, J., Alvarez, B. \& Nemirovsky, M. (1964) Histo-immunological localization of hyaluronidase in the bull testis. $J$. Reprod. Fert. 8, 325-330.

Meistrich, M.L., Trostle, P.K., Frapart, M. \& Erickson, R.P. (1977) Biosynthesis and localization of lactate dehydrogenase $X$ in pachytene spermatocytes and spermatids of mouse testes. Devl Biol. 60, 428-441.

Monesi, V. (1965) Synthetic activities during spermatogenesis in the mouse. RNA and protein. Expl Cell Res. 39, 197-224.

O'Brien, D.A. \& Bellvé, A.R. (1980a) Protein constituents of the mouse spermatozoon. 1. An electrophoretic characterization. Devl Biol. 75, 386-404.

O'Brien, D.A. \& Bellvé, A.R. (1980b) Protein constituents of the mouse spermatozoon. II. Temporal synthesis during spermatogenesis. Devl Biol. 75, $405-418$.

O'Farrell, P.H. (1975) High resolution two-dimensional electrophoresis of proteins. J. biol. Chem. 250, 4007-4021.

Sosa, A., Altamirano, E., Hernández, P. \& Rosado, A. (1972) Developmental pattern of rat testis hexokinase. Life Sciences 11, 499-510.

Stambaugh, R. \& Buckley, J. (1969) Identification and subcellular localization of the enzymes affecting penetration of the zona pellucida by rabbit spermatozoa. J. Reprod. Fert. 19, 423-432.

VandeBerg, J.L., Cooper, D.W. \& Close, P.I. (1977) Testis specific phosphoglycerate kinase B in mouse. J. exp. Zool. 198, 231-240. 